\title{
DIREITO E LINGUÍSTICA: DIÁLOGOS INTERDISCIPLINARES NA ANÁLISE DE TCC DA ÁREA JURÍDICA ${ }^{1}$
}

\author{
Webert Cavalcanti Barros* \\ Regina Celi Mendes Pereira**
}

\begin{abstract}
Resumo: O presente trabalho tem como objetivo geral refletir acerca do fazer científico no âmbito do Direito (NOBRE, 2009; FRANÇOIS OST, 2015) e investigar, mais especificamente, como o elaborador de monografia enquanto TCC tem lidado com a escrita acadêmica e com os temas elegidos para discussão. A pesquisa ancorouse no arcabouço teórico-metodológico do ISD (BRONCKART, 1999), na teoria do agir comunicativo (HAMERMAS, 2012[1981]) e em teorias envolvendo gêneros textuais (MARCUSCHI, 2008; 2007; BAKHTIN, 2003[1979]). Para o presente trabalho, selecionamos três TCC de Direito Penal, elaborados em 2014 por alunos do CCJ/UFPB. Alguns resultados têm indicado um fazer científico bastante peculiar na área do Direito, a exemplo de textos comumente utilizados na área poderem servir tanto como corpus de investigação quanto como fonte para embasar teoricamente uma pesquisa.
\end{abstract}

Palavras-chave: O fazer científico. Direito e Linguística. Escrita acadêmica. TCC.

\begin{abstract}
This study has the general objective to reflect on the scientific work in the area of Law (NOBRE, 2009; FRANÇOIS OST, 2015) and investigate, more specifically, how the writer of monograph presented as a Final Course Assignment has dealt with the academic writing and with the topics chosen for discussion. The research is anchored in the theoretical and methodological framework of the ISD (BRONCKART, 1999), in the theory of communicative action (HAMERMAS, 2012 [1981]) and in theories involving textual genres (MARCUSCHI, 2008; 2007; BAKHTIN, 2003 [1979]). For this work, we selected three TCC of Criminal Law, written in 2014 by students from the CCJ / UFPB. Some results have indicated a rather peculiar scientific work in the area of Law, for instance, for certain texts commonly used in the area could serve both as a corpus of research and as a source to base theoretically a research.
\end{abstract}

Keywords: The scientific work. Law and Linguistics. Academic writing. Final Course Assignment.

\section{Introdução}

A articulação entre pesquisa, extensão e ensino tem sido uma tônica no âmbito acadêmico, certamente por possibilitar aos graduandos certo aprofundamento nos conhecimentos que não se limitam apenas ao espaço da sala de aula nem muito menos aos muros universitários. Acrescente-se a essa ideia a de que a produção do conhecimento científico é tecida a partir de uma complexa rede de ações e relações reverberada nos gêneros que circulam nas mais diversas esferas do conhecimento humano.

A propósito, essa tem sido uma das preocupações do presente estudo, o qual se vincula a um projeto mais amplo, a saber, o Ateliê de Textos Acadêmicos (ATA/PROLING/DLCV/UFPB) que tem investigado como o conhecimento científico tem sido desenvolvido em diferentes áreas, sendo que, na presente pesquisa, em verdade, um recorte de tese de doutoramento, objetivou-se compreender, por meio de um diálogo com a Linguística, como esse fazer científico tem sido desenvolvido na área do Direito e, de um

\footnotetext{
${ }^{1}$ Esta pesquisa configura-se como um recorte de tese de doutoramento, sob a orientação da Profa. Dra. Regina Celi Mendes Pereira, pelo Programa de pós Graduação em Linguística (PROLING), da Universidade Federal da Paraíba (UFPB).

* Doutorando em Linguística pelo Programa de Pós-Graduação em Linguística (PROLING) da Universidade Federal da Paraíba. Endereço eletrônico: webertbarros@ gmail.com

** Professora do PROLIING/UFPB e coordenadora do Projeto Ateliê de Textos Acadêmicos (ATA), ao qual o presente trabalho se vincula. Endereço eletrônico: reginacmps@gmail.com
} 
modo mais específico, a partir da análise de TCC da área em questão, como o elaborador do texto, consubstanciado na figura do enunciador, tem-se apropriado dos temas elegidos para discussão, que tratamento tem dado a eles e como tem erigido a discussão sobre tais temas.

Convém esclarecer que o termo geral TCC pode se referir a diferentes gêneros textuais. Consoante Henriques e Medeiros (2014), convencionou-se utilizá-lo para se referir a trabalhos elaborados ao término de cursos de graduação ou especialização. Em muitos cursos, é solicitada a elaboração de uma monografia. Daí, a estreita relação entre trabalho monográfico e TCC. No entanto, a depender da área, não só a monografia é solicitada como requisito para conclusão de curso. Cursos de Direito, por sinal, podem se valer tão somente de uma disciplina de Prática Jurídica para conceder o título de graduado ao aluno. Levando-se em consideração o conceito de gênero prelecionado por Marcuschi (2007; 2008), cabe ressaltar a relevância da função de um gênero, em relação ao seu formato comumente aceito e/ou praticado pela comunidade acadêmica. Assim, a função do que se espera por um trabalho realizado ao término de um curso, quer seja de graduação, quer seja de especialização, pode estar consubstanciada na elaboração de diferentes formatos ou gêneros acadêmicos.

Nesse contexto, a escrita acadêmica tem um papel relevante: primeiramente porque, ainda que certos estudantes possam ter uma escrita já bem desenvolvida, ao ingressarem na universidade, deparam-se com uma nova realidade, a qual não lhes deixa de apresentar novos desafios de aprendizagem e de saber lidar com a escrita. Em segundo lugar, inserida que está nas ações de letramento, as quais dizem respeito às "práticas sociais de uso da escrita" (KLEIMAN, 2005, p. 21), essa escrita se dá por meio dos gêneros cuja aprendizagem é fundamental para se agir em sociedade (KLEIMAN, 2007, p. 9).

Levando-se em conta o conceito de letramento acima, esta pesquisa se insere ainda no âmbito da Linguística Aplicada (LA), considerada enquanto "um modo de criar inteligibilidade sobre problemas sociais em que a linguagem tem um papel central" (MOITA LOPES, 2006, p. 14). Ademais, conforme se pode depreender de Moita Lopes (2009, p. 21), ao dizer que "somos os discursos em que circulamos, o que implica dizer que podemos modificá-los no aqui e no agora.", a LA preconiza a ideia de que, por meio dos gêneros, eventualmente, pode-se gerar mudança da realidade social, o que é pertinente ao que se propõe a investigar neste estudo, já que, em outros termos, assim como o contexto acadêmico interfere no modo com que os textos são elaborados, esses textos, por sua vez, também podem intervir no modo como o conhecimento científico é desenvolvido no âmbito acadêmico.

$\mathrm{Na}$ área jurídica, autores, a exemplo de Varella e Roesler (2012), Nobre (2009) e François Ost (2015) têm apontado para certas lacunas envolvendo a pesquisa em Direito. Nobre (2009), a partir de Ferraz Jr. (1977), em particular, chama a atenção para a problemática de se confundir, nesse contexto, prática profissional com pesquisa acadêmica. Por outro lado, até que ponto o que se faz nessa área não pode ser considerado como um fazer científico? Conforme os postulados gerais do Interacionismo Sociodiscursivo (ISD), teoria de base do presente estudo, compreender os textos, por meio dos quais o homem age em sociedade, estabelecendo um diálogo com o conhecimento proveniente de outras áreas, vai ao encontro de um de seus mais ambiciosos objetivos: compreender o humano (BRONCKART, 2006, p. 10). Questionamentos envolvendo o fazer científico, com intuito menos normativo que de compreensão do modo como esse fazer é desenvolvido na área do Direito, portanto, passa a ser uma via a se percorrer nesta pesquisa, levando em conta que, por meio de seu agir comunicativo (HABERMAS, 2012/1981; 2013/1978; BRONCKART, 1999), o homem desenvolve seu conhecimento dialogicamente (BAKHTIN, 2003/1992).

Para a presente análise de natureza qualitativo-interpretativista e de base documental, foram selecionados três TCC de Direito Penal, abordando diferentes temáticas, defendidos no ano de 2014, pelo Centro de Ciências Jurídicas (CCJ), da Universidade Federal da Paraíba (UFPB). O interesse por pesquisar TCC se deu a partir da pesquisa sobre gêneros acadêmicos 
elaborados em diferentes áreas do conhecimento realizada, conforme sinalizado, pelo ATA. Nesse grupo, o pesquisador tem-se detido na análise de artigos acadêmicos elaborados na área de Direito. Em sua tese, elegeu-se, então, outro gênero a ser investigado e que tivesse relevância para o letramento acadêmico de alunos de graduação, os quais, em comparação aos estudantes de pós-graduação, estão se iniciando em processos de pesquisa. Optou-se por investigar mais de uma área de Direito, a saber, Direito Constitucional, Direito Civil, Direito Penal, Direito Tributário e Direito do Trabalho, por serem áreas comumente abordadas nos TCC desenvolvidos no referido centro universitário. O recorte realizado para a presente pesquisa justifica-se pelo fato de a pesquisa na tese ter-se iniciado pela análise de TCC de Direito Penal, assim como o objetivo neste artigo ser o de apresentar algumas reflexões iniciais.

\section{Direito, linguística e a compreensão do fazer científico}

A escrita acadêmica assume um papel social de grande relevância uma vez que é por meio dela que se registra e se dissemina conhecimentos desenvolvidos e adquiridos em um processo de estudo, pesquisa. Ao término de um curso de graduação, por exemplo, certo estudo pode ser materializado por meio de um trabalho monográfico, o qual é comumente referenciado pelo termo Trabalho de Conclusão de Curso (TCC). Há outros tipos de trabalhos científicos, ou, em outras palavras, é possível materializar pesquisas científicas por meio de diferentes gêneros textuais, a exemplo do artigo científico ou do relatório de projeto de pesquisa. Independentemente do gênero do qual a academia venha a se valer, conforme Henriques e Medeiros (2014, p. 10, grifo nosso) prelecionam: "melhor seria denominar os trabalhos de graduação ou colegiais de trabalhos de iniciação à ciência, passo necessário para alcançar o estágio da pesquisa científica."

Nobre (2009), a partir de Ferraz Jr. (1977), tem apontado para a problemática de se confundir prática profissional com pesquisa acadêmica na área do Direito, ressaltando o seu relativo atraso, em termos de pesquisa, em relação às demais disciplinas de ciências humanas. $\mathrm{O}$ autor chega a afirmar que:

os parcos contatos de teóricos do direito com especialistas de outras disciplinas não podem ser contados como interdisciplinaridade, já que, em lugar de autêntico debate e diálogo, com mudança de posicionamento e de opiniões, encontramos os teóricos do direito no mais das vezes na posição de consultores e não de participantes efetivos de investigações interdisciplinares (NOBRE, 2009, p. 6).

Esse problema se estende ao ensino devido ao "fato de o ensino jurídico estar fundamentalmente baseado na transmissão dos resultados da prática jurídica de advogados, juízes, promotores e procuradores, e não em uma produção acadêmica desenvolvida segundo critérios de pesquisa científica" (NOBRE, 2009, p. 7). O que, por tabela, acaba gerando a confusão supracitada. Então, o autor chega a apresentar uma "concepção alternativa de pesquisa jurídica" (p. 3), configurando-se em uma ampliação do conceito de dogmática jurídica:

Trata-se antes de ampliar o conceito de dogmática e, portanto, seu campo de aplicação, de modo que os pontos de vista da sociologia, da história, da antropologia, da filosofia ou da ciência política não sejam exteriores, tampouco "auxiliares", mas se incorporem à investigação dogmática como momentos constitutivos. (NOBRE, 2009, p. 12, grifo do autor). 
François Ost (2015), por sua vez, elabora uma relevante reflexão sobre o fazer científico, em particular, quando da elaboração de teses de doutorado na área do Direito. Para o autor, muito do que se tem produzido na área pode ser percebido como um "plano de duas partes", ou seja:

ausência de uma verdadeira problemática de pesquisa, como se o exercício se limitasse à exposição de uma questão já resolvida. (...) limitando-se a implantar, de acordo com uma ordem convencional e imutável, os argumentos a favor e contra que fazem o equilíbrio das controvérsias acadêmicas. (FRANÇOIS OST, 2015, p. 104a-104b).

Esse pensamento reforça o que é colocado por Nobre (2009) acerca do que de fato seja um projeto de pesquisa interdisciplinar, e que, portanto, envolva abertura ao movimento dialético, a toda verdadeira descoberta, ao que outros campos de investigação científica também têm a dizer. Certamente, outras áreas também enfrentam esse tipo de problema. $\mathrm{E}$ chega a ser revigorante quando, ao tratar do método de pesquisa, o autor apresenta a ideia de que:

a rota mais promissora não é, necessariamente, o caminho correto, pois as descobertas mais interessantes se fazem nos desvios - o que torna suficiente, para se convencer, a comparação entre um trajeto percorrido na autoestrada e, ao contrário, tomando as estradas nacionais ou departamentais, viajando pelas rotas do interior. Um caminho retilíneo não dará a vocês algo que vocês já não viram ou, em todo caso, o que outros já pesquisaram. A pesquisa comporta uma parte necessária de surpresas, de descobertas. A riqueza de resultados será, frequentemente, à medida das suas inquietações (sobretudo no início do curso), mesmo que seja um sentimento de circular em meio ao nevoeiro. (FRANÇOIS OST, 2015, p. 100b).

Outra pesquisa que revela de modo mais direto a problemática exposta acima é a dos autores Varella e Roesler (2012). A partir de um corpus composto por 169 trabalhos científicos, em particular, de dissertações de mestrado e teses de doutorado, elaborados entre 2007 e 2009, de diferentes programas de pós-graduação em Direito, constatou-se que menos de um por cento das citações/referenciações realizadas nesses trabalhos dizem respeito a outros trabalhos de mestrado e/ou doutorado. A maior parte dos trabalhos referenciados são livros - um bom número deles, inclusive, fruto de algum trabalho de doutorado - os quais não são garantia de serem relevantes para a área, já que, devido a questões de mercado editorial, pode-se pagar por uma publicação de um trabalho que não necessariamente seja fruto de uma pesquisa relevante para a área. Ressalte-se que os autores consideram como livros os trabalhos monográficos "que apresentam uma temática definida, aprofundando-a e não se dedicando a uma conceituação geral dos institutos e problemas jurídicos de determinada subárea do Direito, caso em que o livro foi considerado como manual." (VARELLA; ROESLER, 2012, p. 678).

Esse é um dado concreto que sinaliza para o modo como a pesquisa vem sendo realizada nessa área. Para os autores, em tese, os trabalhos realizados, por exemplo, na pósgraduação, deveriam ser mais referenciados, ao se iniciar uma nova pesquisa, por se tratarem de trabalhos mais recentes, servindo como um interessante "arsenal" para se desenvolver o estado da arte, ou seja, o levantamento do que se tem empreendido em termos de reflexão acerca de certo tema. E isso, certamente, deve valer também para o caminho metodológico que se traça na graduação, ao se iniciar uma pesquisa.

Por outro lado, pensando no Qualis ou classificação à qual são submetidos os 
periódicos e as revistas de divulgação científica, Varella e Roesler (2012) questionam se não seria contraproducente mobilizar toda uma área para se adequar a certos critérios de classificação sem levar em conta o que de fato é produzido e referenciado na área de Direito. Isso porque um dos critérios que define a qualidade das revistas e, mais especificamente, dos artigos contidos nessas revistas, é o número de vezes que são referenciados em outros trabalhos. A pesquisa dos autores supracitados revela que esses periódicos, a exemplo das dissertações e teses, são igualmente pouco referenciados na área em questão, em comparação aos livros. Daí, a pertinência do questionamento que os autores fazem.

Essa ideia vai ao encontro do que ora se pretende defender, a saber, o estabelecimento de um diálogo com a Linguística; porém, com um olhar menos normativo e mais compreensivo sobre como o conhecimento científico vem sendo desenvolvido em Direito. Conforme sinalizado, o ISD, arcabouço teórico-metodológico que embasa o presente estudo, aborda a complexa rede de conhecimentos de diferentes áreas em jogo e que devem ser mobilizados ao se analisar textos, em particular, escritos. As monografias elaboradas para conclusão de curso em Direito são um exemplo disso, pelo fato de o processo de sua elaboração propiciar o estabelecimento de um diálogo com outras áreas, conforme ocorre em pesquisas envolvendo Direito Penal, as quais por vezes podem levar o pesquisador a recorrer a conhecimentos da área da Psicologia. Ademais, ainda que não se problematize as questões, conforme colocado por François Ost (2015), certamente possui a vantagem de servir enquanto "trabalho de inciação à ciência", segundo apontam Henriques e Medeiros (2014).

Ao se analisar textos, na perspectiva do ISD, leva-se em conta a interrelação de elementos constitutivos de sua tessitura. Um texto constitui-se, portanto, do que nessa corrente teórico-metodológica é concebido como "folhado textual" (cf. BRONCKART, 1999), o qual, em forma de camadas não necessariamente sobrepostas, e sim essencialmente interrelacionadas, corresponderiam a um nível mais profundo, outro intermediário e outro de superfície do texto, os quais, respectivamente, dizem respeito à infraestrutura, mecanismos de textualização e mecanismos enunciativos, conforme se pode apreender, a partir do gráfico seguinte.

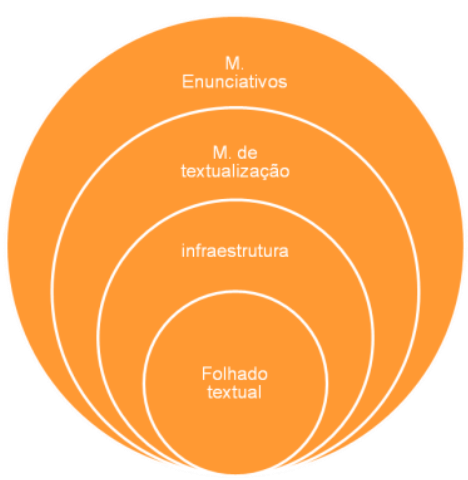

Gráfico 1: Representação do Folhado Textual do ISD

Fonte: PEREIRA, Regina Celi Mendes (2010, p. 186) com base em Bronckart (1999).

Os dados de infraestrutura estão mais diretamente relacionados ao plano geral da arquitetura textual, o qual diz respeito ao conteúdo temático e ao modo de disposição de tal conteúdo ao longo de um texto. Essa disposição tem a ver com o tipo discursivo de base mais ou menos predominante em um texto. Conforme postulados do ISD, o discurso predominante pode pertencer mais a uma ordem expositiva ou, então, narrativa, respectivamente, aproximando-se do mundo material do produtor empírico do texto, ou, por vezes, reproduzindo um discurso mais distanciado dos parâmetros materiais de produção do texto, 
porém, baseando-se nesses parâmetros para representar mundos criados, a exemplo das histórias relatadas em obras literárias. Os mecanismos de textualização, por sua vez, estão relacionados às relações nominais e verbais estabelecidas no texto. Uma monografia, por exemplo, devido à sua linguagem formal, distancia-se dos parâmetros materiais do autor empírico, o qual, apesar de se assumir nos elementos pré-textuais, imprime ao texto um tom mais impessoal, por meio de um tempo que igualmente se distancia do tempo presente desse autor real. É o que geralmente ocorre em textos científicos ou com teor mais teórico, a exemplo do dicionário.

Os mecanismos enunciativos, por sua vez, podem evidenciar os posicionamentos do enunciador cuja responsabilidade nem sempre é assumida pelo produtor do texto. A monografia também serve de exemplo, pois, muito embora assinada por um estudante, por meio do uso de primeira pessoa do plural, apresenta um enunciador plural que não diz respeito unicamente a esse estudante, produtor do texto. Essas questões se tornam ainda mais relevantes se pensarmos que em um trabalho dessa natureza não se deva fazer uso de primeira pessoa do singular, de certo modo, por comportar certo risco assumir sozinho tudo o que é exposto em tal trabalho, mas também, pelo fato de uma pesquisa envolver a somatória de contribuições tanto dos trabalhos e/ou ideias de teóricos abordados na pesquisa, quanto do(s) orientador(es), colegas de estudos etc., com os quais se estabelecem diálogos, trocas de ideias, ainda que por meio de conversas informais, quando do processo de desenvolvimento de sua pesquisa.

Essas questões temáticas, o modo como são recuperadas e tradadas na tessitura do texto, e o quanto o produtor se implica, ou seja, assume ou não o que está posto nesse texto, e a relevância disso para o fazer científico, em particular, na área de Direito, são alguns dos interesses que moveram a presente pesquisa e que poderão ser percebidos mais diretamente na seção seguinte, na qual serão apresentadas as análises de monografias elaboradas nessa área.

Contudo, cabe ressaltar uma ideia pertinente não apenas para a área do Direito, e que, embora desenvolvida por Habermas (2012/1981), no âmbito da Sociologia, mais precisamente, no âmbito das filosofia social e política, foi retomada pelos teóricos do ISD, no âmbito da Psicologia, teóricos estes com as quais certos pesquisadores da Linguística têm estabelecido estreitas reflexões tanto de cunho epistemológico quanto de natureza prática sobre questões de gênero textual, letramento, prática profissional. Para Habermas, o discurso está na base de qualquer entendimento ou contrato que se venha estabelecer, uma vez que não agimos isoladamente em sociedade. O agir comunicativo é retomado pelo ISD como algo constitutivo das ações de linguagem. $O$ homem age por meio dos gêneros textuais engendrados no seio da sociedade e, do mesmo modo como recorre a um arcabouço, a um modelo de um ou outro gênero, a fim de agir na vida, em sociedade, tendo em vista certos objetivos a serem alcançados, sendo, portanto, influenciado pelos modelos já pré-existentes em um contínuo sócio-histórico-cultural das ações humanas, ele mesmo pode vir a interferir nesse fluxo, por vezes, provocando mudanças sociais, a exemplo dos gêneros textuais que passaram a ser utilizados com os mais recentes avanços tecnológicos, e por meio dos quais o homem age e transforma o seu entorno.

Uma monografia, portanto, como quaisquer trabalhos frutos de uma pesquisa, não deve ser concebida tão somente para a aquisição de algum tipo de diploma. Isto posto, é preciso ter em mente que ninguém consegue escrever se não tiver o que escrever ou o que falar (cf. GERALDI, 1984). Ler, então, é um passo. Compreender, um segundo passo. A pesquisa começa a efervescer no espaço entre os atores sociais, entre as pessoas mais diretamente relacionadas com um campo de investigação e os demais pesquisadores pertencentes a diferentes áreas do conhecimento humano. $\mathrm{O}$ fazer científico deve envolver primeiramente uma motivação e uma abertura para uma linguagem o mais dialógica possível. 
Essa postura pode servir para ampliar o campo de visão do pesquisador, sobretudo aquele que esteja iniciando suas pesquisas acadêmicas.

\section{Do tratamento dos dados}

De um corpus que contempla monografias de diferentes áreas do Direito, foram elegidos para a presente análise, parte de uma pesquisa de natureza qualitativointerpretativista, três TCC de Direito Penal, defendidos no ano de 2014, pelo Centro de Ciências Jurídicas (CCJ), da Universidade Federal da Paraíba (UFPB).

Os temas foram escolhidos a partir da leitura dos títulos e, por vezes, dos resumos, levando-se em conta o teor argumentativo. Conforme abordado por François Ost, o discurso tende a se polarizar na área do Direito, consubstanciando-se em argumentos que se posicionam contra ou a favor de certo tema posto em questão. Os temas, portanto, e o modo como são tratados passaram a ressaltar aos olhos do pesquisador, uma vez que poderiam fornecer indícios significativos acerca de como o conhecimento tem sido erigido nessa área, na qual a retórica e o jogo argumentativo são artes tão caras.

Lançou-se, então, um olhar para a infraestrutura textual, apreendendo inicialmente, quais seriam os temas e, então, a partir do sumário, o modo como seriam abordados nas monografias. Em seguida, procurou-se identificar que elementos de pesquisa, a exemplo dos objetivos, contextualização, indicações teóricas e metodológicas, são apresentados ou não nos resumos e de que modo são recuperados na introdução. Observou-se, também, como as discussões empreendidas ao longo da monografia foram conduzidas e de que modo culminaram nas conclusões. Todo esse movimento demonstrando certas peculiaridades do fazer científico na área em questão.

Os temas abordados nos três TCC de Direito Penal selecionados podem ser melhor visualizados no quadro a seguir:

Quadro 1: Temas desenvolvidos nos TCC da área de Direito Penal

\begin{tabular}{|l|l|}
\hline \multicolumn{2}{|c|}{ TEMAS } \\
\hline TCC 1 & MEDIDAS CAUTELARES SUBSTITUTIVAS DA PRISÃO PREVENTIVA \\
\hline TCC 2 & RESSOCIALIZAÇÃO ATRAVÉS DO TRABALHO \\
\hline TCC 3 & PENA DE MORTE \\
\hline
\end{tabular}

Esses temas podem ser desdobrados em tópicos e subtópicos e desenvolvidos gradativamente ao longo do texto, os quais encontram-se refletidos igualmente no sumário. Uma parte significativa de trabalhos acadêmicos é desenvolvida levando-se em conta as prescrições da Associação Brasileira de Normas Técnicas (ABNT). Em termos estéticoestruturais, percebe-se, logo pelo sumário, que os trabalhos ora analisados apresentam uma arquitetura coerente com o que o autor propõe defender e/ou abordar acerca da temática escolhida para discussão.

Assim, os trabalhos tendem a possuir uma parte voltada para a contextualização do tema ou de aspectos mais gerais acerca desse tema e, então, uma parte mais reflexiva ou mais específica corroborando o ponto de vista que pretende defender sobre o tema abordado no trabalho.

Isso pode ser percebido, por exemplo, levando-se em conta o que é enunciado nos tópicos ou capítulos principais, que constam do sumário, apresentados após o capítulo de introdução. 
Quadro 2: Seções de desenvolvimento dos temas abordados em Direito Penal

\begin{tabular}{|l|l|}
\hline \multicolumn{2}{|c|}{ SEÇÕES DE DESENVOLVIMENTO DO TEMA } \\
\hline \multirow{3}{*}{ TC1 1} & 2 A PRISÃO PREVENTIVA COMO MEDIDA CAUTELAR PESSOAL \\
\cline { 2 - 3 } & 3 AS MEDIDAS CAUTELARES DIVERSAS DA PRISÃO PREVENTIVA \\
\cline { 2 - 3 } & 4 A APLICAÇÃO DAS MEDIDAS CAUTELARES FRENTE Ã PRISÃO PREVENTIVA \\
\hline
\end{tabular}

\begin{tabular}{|l|l|}
\hline \multicolumn{2}{|c|}{ SEÇÕES DE DESENVOLVIMENTO DO TEMA } \\
\hline \multirow{4}{*}{ TCC2 } & 2 HISTÓRICO DAS PENAS PRIVATIVAS DE LIBERDADE \\
\cline { 2 - 3 } & 3 INSTRUMENTOS NORMATIVOS VOLTADOS Â PROTEÇÃO DO PRESO \\
\cline { 2 - 3 } & 4 SISTEMA PENITENCIÁRIO, ESTIGMA E REINCIDÊNCIA CRIMINAL \\
\cline { 2 - 3 } & 5 A RESSOCIALIZAÇÃO DOS PRESOS ATRAVÉS DO TRABALHO \\
\cline { 2 - 3 } & 6 ANÁLISE DO SISTEMA PENITENCIÁRIO PARAÍBANO \\
\hline
\end{tabular}

\begin{tabular}{|l|l|}
\hline \multicolumn{2}{|c|}{ SEÇÕES DE DESENVOLVIMENTO DO TEMA } \\
\hline \multirow{3}{*}{ TCC3 } & 2 EVOLUÇÃO HISTÓRICA DA PENA DE MORTE \\
\cline { 2 - 2 } & 3 ASPECTOS GERAIS DA PENA DE MORTE \\
\cline { 2 - 3 } & 4 A PENA DE MORTE NO DIREITO PENAL MILITAR \\
\hline
\end{tabular}

Na primeira monografia, nos dois primeiros capítulos de desenvolvimento são tecidas, respectivamente, considerações acerca da prisão preventiva enquanto medida cautelar e outras medidas cautelares que não unicamente a prisão preventiva, demonstrada de modo mais incisivo no capítulo seguinte, para, então, corroborar a sua defesa, a saber, a de que outras medidas cautelares devam ser preferíveis em relação à prisão preventiva, com as devidas ressalvas a depender de cada caso concreto.

$\mathrm{Na}$ segunda, nos três primeiros capítulos principais são apresentados o quadro histórico e toda uma contextualização envolvendo as penas privativas de liberdade. A ideia defendida no trabalho vai ganhando contornos mais acentuados no capítulo seguinte, quando do direcionamento da discussão para a reflexão sobre a ressocialização dos presos por meio do trabalho, e adquirindo um desfecho mais relevante no último capítulo, ao abordar a problemática em um contexto mais específico.

Do mesmo modo, na terceira monografia, nos dois primeiros capítulos são erigidas discussões mais gerais e de contextualização sobre o tema, a saber, envolvendo a pena de morte, para, então, culminar no questionamento acerca de sua aplicabilidade ainda que em contextos de guerra declarada, conforme previstos na Carta Magna de 1988 e disciplinado pelo Código Penal Militar.

Contrastando o que é apresentado no resumo, "a porta de entrada" para acessar informações sobre o trabalho realizado, com o que é retomado logo na introdução, passa-se, então, a conferir como certos elementos de pesquisa são tratados na área em questão.

As normas técnicas da ABNT, mais precisamente, a NBR 6028, que estabelece os requisitos para redação e apresentação de resumos, no item 2.6, acerca do resumo informativo, ou resumo acadêmico, orienta o leitor quanto aos elementos comumente requeridos para a sua elaboração, definindo-o enquanto gênero que "informa ao leitor finalidades, metodologia, resultados e conclusões do documento, de tal forma que este possa, inclusive, dispensar a consulta ao original."

É nesse sentido que o resumo deve espelhar, ainda mais resumidamente que a própria 
introdução, o trabalho como um todo. Não obstante tais prescrições, por vezes, pode-se perceber a ausência de um ou outro elemento nos resumos acadêmicos. Isso pode se dar por diferentes razões, desde falta de habilidade com a escrita acadêmica até por questões mais amplas relacionadas à própria natureza da pesquisa que se esteja desenvolvendo, ou ainda, devido a interferências da própria área. De outro modo, tais elementos podem estar implícitos na tessitura do texto, e não necessariamente aparecerem na ordem de exposição prescrita pela ABNT. A seguir, algumas considerações sobre o modo como os alunos de Direito lidaram com esses elementos quando da elaboração do resumo e demais seções dos TCC selecionados ${ }^{2}$.

No resumo do TCC1, percebe-se a apresentação do(s) objetivo(s): "analisar a possibilidade da aplicação das medidas cautelares substitutivas da prisão preventiva promover uma redução da população carcerária brasileira"; a contextualização do tema e esclarecimento quanto ao objeto de estudo: "as medidas cautelares não prisionais"; a indicação dos aportes teórico-metodológicos: "Lei n. 12.403", "Código de Processo Penal (CPP)", "estudo interpretativo e bibliográfico"; assim como a hipótese e resultados da pesquisa: "demonstrou-se que as medidas cautelares substitutivas do cárcere podem ser um eficiente instrumento utilizado para amenizar a problemática carcerária, desde que o Estado dê condições e regulamente as atividades fiscalizatórias dessas medidas".

No resumo do TCC2, por sua vez, têm-se o(s) objetivo(s): "analisar historicamente o sistema prisional brasileiro e paraibano, levando em consideração a ressocialização como fator primordial para redução de reincidências e da criminalidade. Tem como finalidade a análise do impacto do trabalho e profissionalização de apenados como condições para viabilizar seu ingresso no convívio social"; a indicação do corpus de análise: "políticas públicas de ressocialização", "programas de laboraterapia e profissionalizantes"; a hipótese ou tese defendida: "que o trabalho do encarcerado e egresso é requisito essencial para o processo de ressocialização, oportunizando-se estes indivíduos o exercício de uma atividade produtiva, com a finalidade de reinseri-los na sociedade de forma digna"; o objeto de estudo: "o sistema penitenciário paraibano contemporâneo"; e uma possível indicação da natureza da pesquisa: "pensar crítico".

No resumo do TCC3, são apresentados o objeto de pesquisa: "pena de morte no Brasil e no direito comparado"; a indicação metodológica: "análise comparativa"; uma antítese, a saber, a de que: "a pena de morte tem sido adotada por poucos países, estes denominados retencionistas, por acreditarem que esta sação cumpre com a finalidade geral da pena, ou seja, a prevenção de crimes e sua retributividade, bem como por ser mais econômica que a pena privativa de liberdade, ter efeito intimidativo, ser rápida, não gerar dor, não produzir sequelas nos envolvidos e ser eficaz no combate ao crime" e uma tese, a saber, a de que: "a pena máxima, como também é conhecida a pena de morte, distancia-se e muito de sua finalidade, tendo em vista a crueldade com que é aplicada, não sendo proporcional ao crime; não ajuda na prevenção de delitos, por não ter efeito intimidativo; é custosa para o Estado e para o direito; é lenta, dolorosa e gera uma tortura psicológica incomensurável; e não combate a criminalidade. Além de todos esses aspectos negativos, a pena capital é irreversível, pois, uma vez aplicada, não pode ser revertida. Nesse contexto, encaixa-se o problema do erro judiciário, frequente nos dias de hoje, e o problema da irreparabilidade deste erro quando se lida com a vida de um inocente."

$\mathrm{O}(\mathrm{s})$ objetivo(s) e uma possível hipótese são, então, apresentados na parte final do resumo: "pretende-se, por meio do presente trabalho, demonstrar a total inutilidade da pena capital, no que diz respeito à sua aplicação tanto nos crimes comuns quanto nos delitos militares em caso de Guerra declarada, e apontar como solução a sua substituição pela pena

\footnotetext{
${ }^{2}$ A título de esclarecimento, os trechos apresentados neste artigo foram transcritos tal como se encontram nos TCC analisados.
} 
privativa de liberdade, com algumas cautelas."

Contudo, antes da apresentação do(s) objetivo(s), consta do resumo que o estudo "por meio de uma pesquisa de campo", verifica entre participantes civis e militares dados referentes à aceitação da execução da pena em períodos de guerra declarada, o que chega a levar o leitor a pensar que se trata de algum procedimento metodológico empreendido pelo autor do TCC. Em verdade, conforme constatado no capítulo da introdução, trata-se mesmo de pesquisa realizada por outro autor da qual valeu-se o autor dessa monografia. Esse é um dado relevante, uma vez que pesquisa de campo na área do Direito não se dá do mesmo modo que na área da Linguística. Nesta, por exemplo, costuma-se observar a prática de um docente, para analisá-la à luz de alguma teoria. Naquela, por vezes, são analisados processos, nos quais relatam-se casos que já foram julgados; um pesquisador não poderia acompanhar o processo de um caso a ser julgado, por envolver dados, por vezes, confidenciais.

No TCC analisado, a pesquisa de campo referenciada diz respeito a uma entrevista realizada por um dos teóricos aos quais o estudante recorreu para embasar seu estudo monográfico, o que, de certo modo, extrapola a simples análise de textos escritos, como no caso dos processos. Em todo caso, pensar em alternativas de como realizar pesquisa de campo no Direito, a exemplo do que se faz na Linguística, poderia contribuir para se compreender, entre tantas outras coisas, didáticas de ensino das disciplinas jurídicas.

Percebe-se que nos três TCC os elementos relacionados a questões metodológicas são abordadas de maneira mais detalhada na introdução, tanto o é que o termo "por meio de uma pesquisa de campo" utilizado no resumo do TCC sobre pena de morte perde a ambiguidade, já que na introdução fica claro que não se tratava de um procedimento metodológico utilizado pelo autor do TCC, mas de uma pesquisa da qual esse autor se valeu para desenvolver suas reflexões sobre esse tema em sua monografia.

Leis e/ou códigos referenciados nesses trabalhos são utilizados tanto como corpus de análise quanto para embasar as discussões. Levando-se em conta as temáticas abordadas, uma ou outra lei pode servir mais exclusivamente como corpus de análise, enquanto que outras eventualmente somadas a essa adquirem um status mais de fundamentação teórica, como no caso de doutrinadores referenciados nos TCC. O resumo sobre a pena de morte pode servir para ilustrar a fala de François Ost (2015) acerca dos debates envolvendo os prós e contra relacionados a certo tema. No geral, as questões apresentadas nos capítulos principais desses TCC são praticamente uma versão mais bem desenvolvida do que é posto na introdução.

Certamente, as pesquisas podem avançar ainda mais, em termos de problematização, partindo de uma situação-problema, transformada em uma questão de pesquisa, para qual se busque uma resposta. Porém, chama a atenção, particularmente, a maneira como o autor do TCC3 chega a se implicar na seção das conclusões: "A meu ver, esta é uma das mais graves consequências desta penalidade". E mais adiante: "(...) não concordo com este posicionamento e me filio à abolição completa da pena de morte em todos os países". $\mathrm{O}$ produtor se assume enquanto enunciador do texto. Dada a maneira como tece a discussão, retomando os dados contra a aplicação da pena capital, a conclusão lhe serve como uma micro-ação retórica, a fim de afirmar seu posicionamento acerca da questão colocada em discussão.

Autores mais experientes, a depender de seu estilo, podem se valer desse tipo de posicionamento em primeira pessoa do singular, para veicular suas ideias nos textos que elaboram. Na cultura francesa, por exemplo, pode ser até mais recorrente. O que pode se tornar crítico é ficar oscilando entre as pessoas do discurso, ora se valendo da primeira pessoa do discurso, ora da terceira, e, em ambos os casos, tanto do singular quanto do plural. Porém, dada a relevância dos exercícios retórico e argumentativo na área do Direito e o fato de esses trabalhos monográficos poderem servir como uma "iniciação à ciência", o modo como o autor do TCC3 trata o tema elegido para discussão em seu texto, independentemente de sua 
implicação em primeira pessoa do singular, indicia o que muito se busca na academia: discursos no mínimo coerentes, de quem prima pela competência, de quem busca se fazer autoridade naquilo sobre o que se propõe estudar. Enquanto ensaio para o exercício científico, os três textos revelam certa verticalização em termos de leitura, a qual, por sua vez, evidencia que os alunos procuraram fazer bem o dever de casa, a saber, o de um levantamento do estado da arte dos assuntos abordados nos TCC, com a vantagem de que a busca de um desenvolvimento retórico na escrita pode conferir o desenvolvimento de um pensamento mais acurado, crítico, reflexivo, o que, por tabela, embora não seja garantia, pode contribuir para o desenvolvimento da oratória, tendo em mente a defesa oral do trabalho monográfico.

Ademais, o aperfeiçoamento técnico de questões textuais se dá nas práticas de letramento, nas micro-ações empreendidas em um processo de investigação que culmina na materialização de um gênero acadêmico, a exemplo do TCC, nas relações dialógicas (BAKHTIN, 2003/1992; BAKHTIN/VOLOCHINOV, 2010/1988) que são estabelecidas entre os pares e demais pesquisadores de outras áreas, nas ações de linguagem (BRONCKART, 1999) ou agir comunicativo (HABERMAS, 2012/1981), por meio do qual o homem estabelece acordos, assim como produz seu conhecimento sócio-histórico e cultural.

\section{0 que se conseguiu auferir até o momento}

No presente estudo, foram analisados três TCC da área de Direito Penal, buscando-se estabelecer um diálogo com a Linguística, assim como compreender o modo como o fazer científico é desenvolvido na área do Direito. Vale ressaltar que a rede interdisciplinar proposta neste trabalho não necessariamente é apreendida a partir dos TCC elaborados por alunos de Direito, mas da contribuição por meio da análise e pesquisa desse corpus de investigação que se quer empreender a partir da área da Linguística. De um modo mais específico, objetivou-se compreender, a partir da análise desses trabalhos, como o elaborador do texto, consubstanciado na figura do enunciador, tem-se apropriado dos temas elegidos para discussão, que tratamento tem dado a eles e como tem erigido a discussão sobre tais temas.

Percebe-se que a arquitetura geral dos trabalhos analisados é coerente com os objetivos que cada autor pretendeu alcançar. Alguns resultados têm indicado um fazer científico bastante peculiar na área do Direito, a exemplo de textos comumente utilizados na área poderem servir tanto como corpus de investigação quanto para embasar teoricamente uma pesquisa. Os temas tendem a ser tratados conforme apontam Nobre (2009) e François Ost (2015), por vezes, por meio de discursos que vão de encontro ou a favor de certo tema.

Contudo, levando-se em conta o caráter transdisciplinar advogado pelo ISD e a peculiaridade do fazer científico da área em questão, ressalte-se aspectos menos normativos e mais compreensivos sobre o modo de construir conhecimento na área do Direito e, mais particularmente, ao se lidar com temas, quando da elaboração de TCC.

As questões de pesquisas poderão ser mais adequadamente realizadas, à medida que novas demandas forem surgindo, inclusive nos espaços entre áreas. Por ora, cabe ressaltar que os TCC analisados devam ser compreendidos enquanto fruto de uma "iniciação à ciência", os quais podem servir, inclusive, para o levantamento do estado da arte, por estudiosos, ao darem início a outras novas pesquisas.

\section{Referências}

ASSOCIAÇÃO BRASILEIRA DE NORMAS TÉCNICAS. NBR 6028: informação e documentação: resumo: apresentação. Rio de Janeiro, 2003. 
BAKHTIN, M. Estética da Criação Verbal. Introdução e tradução do russo: Paulo Bezerra. 4. ed. São Paulo: Martins Fontes, 2003/1992 [1979]. 476 p.

BAKHTIN, M. [VOLOCHÍNOV]. Marxismo e Filosofia da Linguagem. 14. ed. São Paulo : Hucitec, 2010/1988 [1977]. 203p.

BRONCKART, J. P. Atividade de Linguagem, Textos e Discursos: por um interacionismo sociodiscursivo. Tradução: Anna Rachel Machado e Péricles Cunha. São Paulo : EDUC, 1999. $353 \mathrm{p}$.

Atividade de Linguagem, Discurso e Desenvolvimento Humano. Organizado por Anna Rachel Machado et. al. Campinas, SP : Mercado de Letras, 2006.

GERALDI, J. W. O Texto na Sala de Aula. São Paulo: Editora Ática, 1984.

HABERMAS, J. Teoria e Práxis. São Paulo: Editora Unesp, 2013 [1978].

Teoria do Agir Comunicativo, 1: racionalidade da ação e realização social. Tradução de Paulo Astor Soethe. Revisão da tradução Flávio Beno Siebeneichler. São Paulo: Editora WMF Martins Fontes, 2012 [1981].

Teoria do Agir Comunicativo, 2 : sobre a crítica da razão funcionalista. Tradução de Flávio Beno Siebeneichler. São Paulo : Editora WMF Martins Fontes, 2012 [1981].

HENRIQUES, A.; MEDEIROS, J. B. Monografia no Curso de Direito. Como Elaborar o Trabalho de Conclusão de Curso (TCC). 8. ed. São Paulo : Atlas, 2014.

KLEIMAN, A. B. Preciso "ensinar" o letramento? Não basta ensinar a ler e escrever? Cefiel/IEL/Unicamp, 2005-2010. Disponível em: <http://www.letramento.iel.unicamp.br/publicacoes/artigos/preciso_ensinar_letramentoKleiman.pdf>. Acesso em: 15 de fevereiro de 2011.

Letramento e Suas Implicações para o Ensino de Língua Materna. Signo. v. 32, n. 53, p. 1-25, 2007. Disponível em: <http://online.unisc.br/seer/index.php/signo/article/viewFile/242/196>. Acesso em: $15 \mathrm{de}$ fevereiro de 2011.

MARCUSCHI, L. A. Produção Textual, Análise de Gêneros e Compreensão. São Paulo: Parábola Editorial, 2008.

Gêneros Textuais: definição e funcionalidade. In: DIONISIO, A. P.; MACHADO, A. R.; BEZERRA, M. A.. Gêneros textuais e ensino. 5. ed. Rio de Janeiro: Lucerna, 2007. p. 1936.

MEDEIROS, J. B. Redação Científica: a prática de fichamentos, resumos, resenhas. 7a. ed. São Paulo : Atlas, 2005. 328 p.

MOITA LOPES, L. P. da. Uma Lingüística Aplicada Mestiça e Ideológica: interrogando o campo como lingüista aplicado. p. 13-44. In: FABRÍCIO, B. F. et al. Organizador: Luiz Paulo 
da Moita Lopes. Por uma Lingüística Aplicada INdisciplinar. São Paulo: Parábola Editorial, 2006. 279 p.

Da Aplicação de Linguística à Linguística Aplicada Indisciplinar. In: PEREIRA, R. C. M. e ROCCA, M. del P. (Org.). Linguística Aplicada: um caminho com muitos acessos. São Paulo: Editora Contexto, 2009. p. 11-24.

NOBRE, M. Apontamentos Sobre A Pesquisa Em Direito no Brasil. In: CADERNOS DIREITO GV. Biblioteca Digital da Fundação Getúlio Vargas. Brasília, DF. 11 set. 2009. Disponível em: <http://bibliotecadigital.fgv.br/dspace/handle/10438/2779>. Acesso em: jun. 2015.

OST, F. A Tese de Doutorado em Direito: do projeto à defesa. In: Revista de Estudos Constitucionais, Hermenêtica e Teoria do Direito (RECHTD), 7(2): 98-116, maio-ago 2015.

PEREIRA, R. C. M. (Org.). Ações de Linguagem: da formação continuada à sala de aula. 1a. ed. João Pessoa: Editora Universitária UFPB, 2010. 200 p.

VARELLA, M. D.; ROESLER, C. R. Dificuldades de Avaliação de Publicações na Área de Direito. In: RBPG, Brasília, v. 9, n. 18, p. 663 - 701, dez. 2012.

Recebido em: dezembro de 2015.

Aprovado em: março 2016. 